\title{
GROUND MOTION IN YOGYAKARTA CITY, YOGYAKARTA SPECIAL PROVINCE, INDONESIA ON DENSELY MICROTREMOR OBSERVATIONS AND SHEAR WAVE VELOCITY
}

\author{
Zaw Lin Kyaw*1,2, Subagyo Pramumijoyo², Salahuddin Husein², Teuku Faisal Fathani ${ }^{3}$, \\ and Junji Kiyono ${ }^{4}$ \\ ${ }^{1}$ Geology Department, Yangon University, Yangon, Myanmar \\ ${ }^{2}$ Geological Engineering Department, Faculty of Engineering, Gadjah Mada University, Yogyakarta, Indonesia \\ ${ }^{2}$ Civil and Environmental Engineering Department, Faculty of Engineering, Gadjah Mada University, Yogyakarta, \\ Indonesia \\ ${ }^{4}$ Department of Urban Management, Graduate School of Engineering, Kyoto University, Katsura Campus, Nishikyo, \\ Kyoto, Japan
}

\begin{abstract}
Microtremor is currently considered the foremost tool in site effect studies. The ground motion is estimated with microtremor observations, meaning that subsoil mechanical properties and geometry are evaluated and from them an estimate of local amplification is computed. Here, the ground motion is studied by the site effects of seismic hazard zonation of urban areas in Yogyakarta City. The main purpose of this paper is zoning the geological engineering features and assessing seismic of the research urban area. In this regard, the microtremors are measured at 274 sites by single station sampling method and Nakamura technique. The microtremors of all over the city are processed by a model of Mitutoyo-GPL-6A3P. The amplification factor generally ranges between 0.70 and 5.56 and the natural frequency normally varies between 0.40 and 3.30 $\mathrm{Hz}$. The information layers are prepared in GMT used for detecting the zonation of potential seismic hazard. The shear wave velocity is calculated in 12 existing drilling sites based on the geotechnical approach of SPT for soil condition. To study the

${ }^{*}$ Corresponding author: Z. L. KYAW, Department of Geological Engineering, Faculty of Engineering, Gadjah Mada University, Jl. Grafika 2 Yogyakarta, 55281, Indonesia. E-mail: zlkyaw.geol@gmail.com.
\end{abstract}

ground motion, geological engineering condition is investigated using amplification factor, natural frequency, shear wave velocity maps which are analyzed using densely single microtremor observation and SPT from existing drilling sites.

Keywords: Ground motion, amplification factors, natural frequency; $H / V$ spectral ratio, microtremor observations, Yogyakarta Urban.

\section{Introduction}

The Yogyakarta city, the capital of Yogyakarta Special Province, is situated at the southern part of the volcanic arc island of Java. The eastern part of Yogyakarta city is located in the so-called Yogyakarta Depression area, which is only about $30 \mathrm{~km}$ from the Merapi volcano and reaches the elevation of $2911 \mathrm{~m}$ above sea level. Merapi, located $40 \mathrm{~km}$ from the coast of the Indian Ocean, is the most active volcano in Indonesia. The eastern part of Yogyakarta city is situated at the centre of the province, in the middle part of Yogyakarta basin. The Basin response depends on the site geometry, impedance contrast, soil properties and constitutive model, and on the complexity and strength of the input solicitation. An earthquake with $\mathrm{Mw} 6.3$ magnitude oc- 
curred near Yogyakarta city on May 27th 2006 at 5:54 am local time. The earthquake directly affected the provinces of Yogyakarta and Central Java Island. This earthquake caused nearly 6,500 fatalities and above 36,000 injured. More than 135,000 houses were damaged, and 600,000 people were homeless. In this study, the densely single microtremor observation5s are carried out in the eastern part of Yogyakarta City plain and the estimation of ground motion characteristics based on the H/V spectrum and S-wave velocity. It is clearly noticed that the amplification factors and the natural frequency required for the microtremor has effective sediment thickness with soil condition of S-wave velocity.

\section{Geological condition}

The geology around Yogyakarta City is controlled by active plate tectonic phenomena such as the active volcano and active subduction of Indian-Australia oceanic plate below the Eurasia continental plate. To the west, there is a dome of andesitic breccia and lava flows with intensive fault formation. Whereas at the eastern part, steep mountains of carbonaceousvolcanic rocks as well as limestone with karst landscape are exposed. The major structure is the north-east trending normal fault and wellknown Opak fault which defines the eastern limit of a trough extending from Yogyakarta to the coast. The Quaternary succession is dominated by volcanic deposits, largely attributable to Merapi volcano. Other important deposits such as litoral clay deposits in the vicinity of Wates, minor valley and terrace alluvium in the main river valleys, deflation materials on limestone and sand dunes adjacent to the coast have also been encountered. The Yogyakarta unit forms the surface outcrop throughout the lowland area of Yogyakarta Basin from Merapi Middle Slope to the coast. The unit consists of an interbedded sequence of sand, gravels, silts and clay. The amount of clay increases southward. However, the layers of coarse materials have been encountered throughout the basin. Thickness of this unit is variable and up to 45 $\mathrm{m}$ in some places. This unit lies unconformable upon the Sleman unit.

\section{Past earthquake events}

Earthquakes occur almost continuously around the world. Fortunately, most are so small that they cannot be felt. Only a very small percentage of earthquakes are large enough to cause noticeable damage and small percentage of those are large enough to be considered major earthquakes. Throughout recorded history, some of these major earthquakes can be regarded as being particularly significant, either because of their size and the damage they produced or because of what scientists and engineers were able to learn from them.

The Java trench region shows low seismicity compared with the Sumatra subduction zone region but the destructive earthquakes occurred in the past and some of them have generated tsunami. The historical earthquakes record in this area can be generally divided as pre-historical period up to about 1840 with the epicentre locations and magnitudes based largely upon felt reports, and an instrumental period which refers to USGS (NEIC) and ANSS earthquake catalogues. According to the historical and instrumental records, most of the earthquakes which affected the Yogyakarta special province mostly occurred within the radius of $200 \mathrm{~km}$.

Although the southern part of central Java has relatively low seismicity compared to the east Java and the west Java, it does not mean that Yogyakarta have never or rarely experience devastating earthquakes. Beside the latest May 27, 2006 event, historical records indicate that Yogyakarta has been struck several times by the earthquake and significant damages were reported as shown in Figure 1. The Yogyakarta area therefore can be regarded as a seismic prone area and the similar destructive earthquakes can be expected in future. The prevention and mitigation of seismic risk in this area is one of the major needs. 


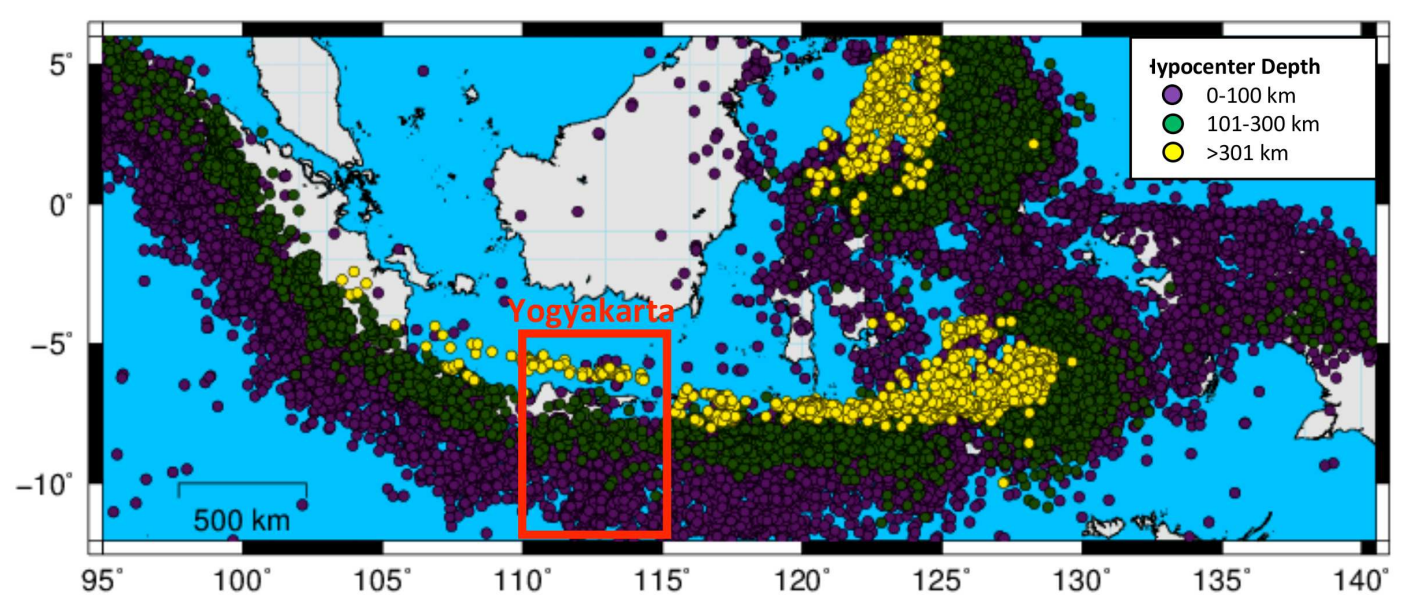

Figure 1: Historical Seismicity in Indonesia (Mw $>4.0$ and 1840-2013).

\section{Microtremor and existing drilling sites}

The earth surface is always in motion at different frequencies; even in the absence of active seismic sources. The damages caused by the recent earthquake are concluded as a direct result of local geological conditions affecting the ground motion. These constant vibrations are called microseisms or preferably microtremors. The amplitude of these microtremors is generally too small (10-4-10-2 $\mathrm{mm})$ to be felt by human senses. Microtremors are considered as noise sources in seismological studies. Microtremor is a very convenient tool to estimate the effect of surface geology on seismic motion without other geological information. Moreover the single microtremor observation methods have been developed as a simple and cost effective method to determine the characteristics of the ground properties (Nakamura, 1989; Tokimatsu et al., 1994).

In today practice, to provide a good coverage of the study area, the measurement sites are designed with a grid spacing of 500 meters to the main path of the north-south and eastwest of the research area to known in detail the configuration soft rocks and contact hard rock. The results of microtremor observations were measured for five minutes by using the sampling rate of $100 \mathrm{~Hz}$ with 3-components. Although they are results from five minutes measurements, it is still enough to get first fundamental period of $\mathrm{H} / \mathrm{V}$ ratio for most of cases.
The first fundamental frequency of $\mathrm{H} / \mathrm{V}$ ratio mostly reflects the $S$-wave velocity of sediments and it is therefore used for validation of S-wave velocity structures determined by geotechnical approach.

Moreover, the single microtremors observations of 274 sites in the eastern part of Yogyakarta City show in the Figure 2(a). The measurements were carried out during the daytime using a microtremor instrument which is model of Mitutoyo-GPL-6A3P and serial No. 0418707. A single seismic station was used for the microtremor measurements. It was composed of a short-period, three-component seismometer with natural period of one second, a 24-bit A/D converter with GPS time, sampling each channel at 100, and a laptop computer to control the system and store the data. At each sites microtremors were recorded with a sampling rate of $100 \mathrm{~Hz}$ for 5 minutes. During the measurements particular attention was given to keep the recordings free from very local noise sources, like e.g. passing pedestrians, vehicles or operating machineries. Meteorological disturbances, e.g., rainfall or gusty wind, did not occur during the observation period. The site's topography and local peculiarities were also considered, e.g., artificial soil replenishments, floor coverings, paved or tarmac roads, and neighbouring elevated structures.

The subsurface geological structures strongly affect on seismic ground motion exist. The subsurface soil structure and related geotechnical 
parameters have been evaluated in the research areas for determination strong ground motion and ground response analyses. The detailed drilling program had been gotten from secondary data for subsurface investigation in Yogyakarta City. The boreholes had been throughout the study area to evaluate the geotechnical properties of subsurface soil layers. The boreholes were generally drilled up to the bedrock. The depths are varying from 20 to $40 \mathrm{~m}$. For the site characterization in the $8 \mathrm{~km} \times 9 \mathrm{~km}$ of the eastern part of Yogyakarta City and twelve borehole investigations were conducted as shown in Figure 2a.

The eastern part of Yogyakarta City sits in a broad valley between two groups of roughly north running mountains, which are Kulon Progo Mountains to the west and Southern Mountains to the east. The towering Merapi volcano caps the northeast end of the valley. Behind that is the single peak of the Sundero volcano and a cluster of small peaks in the Dieng volcano complex as shown in Figure $2 b$.

\section{Analysis of $\mathrm{H} / \mathrm{V}$ spectrum}

A microtremor is a very small ground motion that can be recorded at the ground surface. It can be produced by a variety of excitations (e.g., wind, traffic, breaking sea waves). A full microtremor record can be described by one vertical and two horizontal components. The analysis was conducted by using the recorded microtremor. First, the horizontal component which consists of estimating the ratio between the Fourier amplitude spectra of the horizontal $(\mathrm{H})$ to vertical $(\mathrm{V})$ components of ambient noise vibrations is recorded at one single station as shown in Figures 3(a) and (b). The peak period of the HVSR is known to correspond to the resonant period of the site.

The procedure generally used to calculate the HVSR that consists in the application of Equation (1) to the average amplitude spectra of the three components of motion. This HVSR method postulates the shape of the Fourier spectrum (Nakamura, 2000). Equation (1) shows the method used to calculate HVSR using the observed records (1)

$$
H V S R=\frac{\sqrt{F_{N S_{i}}(\omega)^{2}+F_{E W_{i}}(\omega)^{2}}}{F_{U D_{i}}(\omega)}
$$

where $F_{N S_{i}}(\omega), F_{E W_{i}}(\omega)$ and $F_{U D_{i}}(\omega)$ denote the Fourier amplitude of the NS, EW and UD components of each interval, respectively, and $\omega$ is the frequency.

\section{Transfer function or amplification spectrum}

Earthquake damage is strongly affected by site amplification from bedrock to the ground surface, as well as the size of the earthquake itself. The site amplification of the ground is controlled by factors of the sedimentary layers such as soil density, shear wave velocity, damping characteristics, shape of irregular boundaries, etc. In considering the earthquake disaster prevention measures, knowledge of amplification characteristics and underlying structures of the ground are very important. The peak magnitude of $\mathrm{H} / \mathrm{V}$ ratio is generally correlated to site amplification. However, it is only a rough estimation and the site amplification characteristics determined by response analysis is more acceptable and rational. The ratio of amplification of the Fourier spectrum at two layers is called frequency response function, spectral ratio or amplification factor. Amplification ratio is the amplitude of the objective layer to those of the reference layer and is a function with respect to frequency. The objective layer is chosen to be ground surface and reference layer is base. Thus, frequency at the peak of the spectral ratio corresponds to predominant period of the ground. The inverse of the frequency, i.e., natural predominant period is also obtained.

Nakamura (2000) described his idea on the use of microtremor records for more detailed classification of subsoil conditions. Nakamura's H/V spectrum method postulates that the shape of the Fourier spectrum of the vertical motion is identical between the base rock and the ground surface in Figure 4, while the horizontal motion is subject to significant amplification. Hence, the amplification ratio, AMP, is evaluated by following formula: 


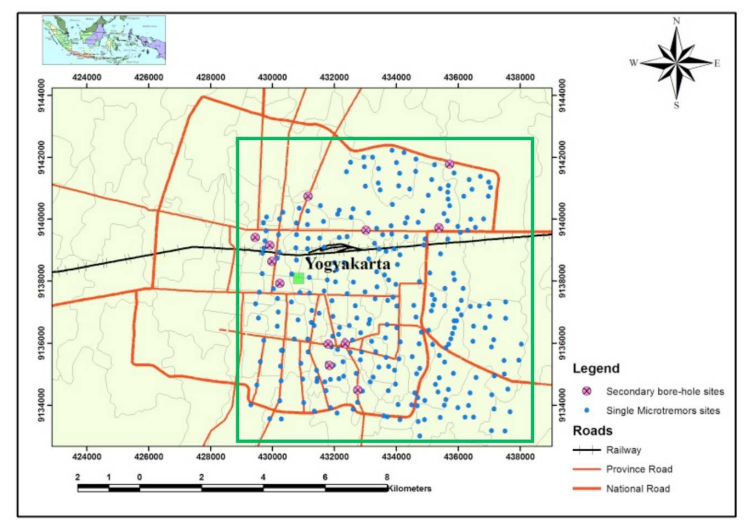

(a)

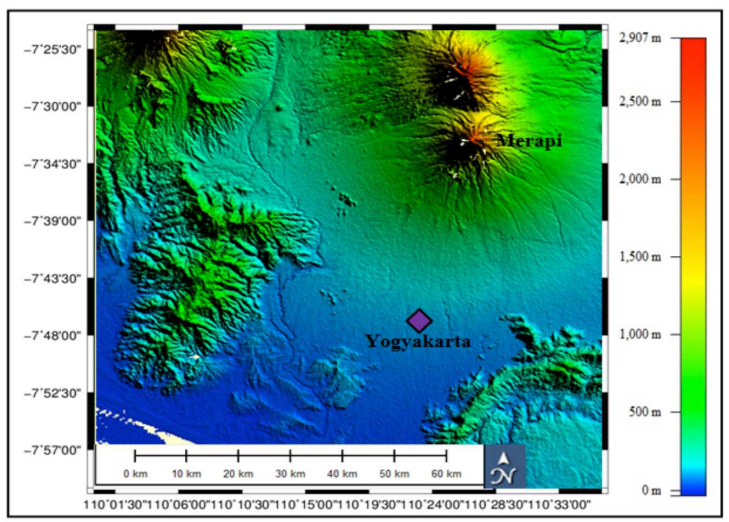

(b)

Figure 2: (a) Station of densely microtremor observations and existing drilling sites and (b) Topography or altitude map in Yogyakarta area
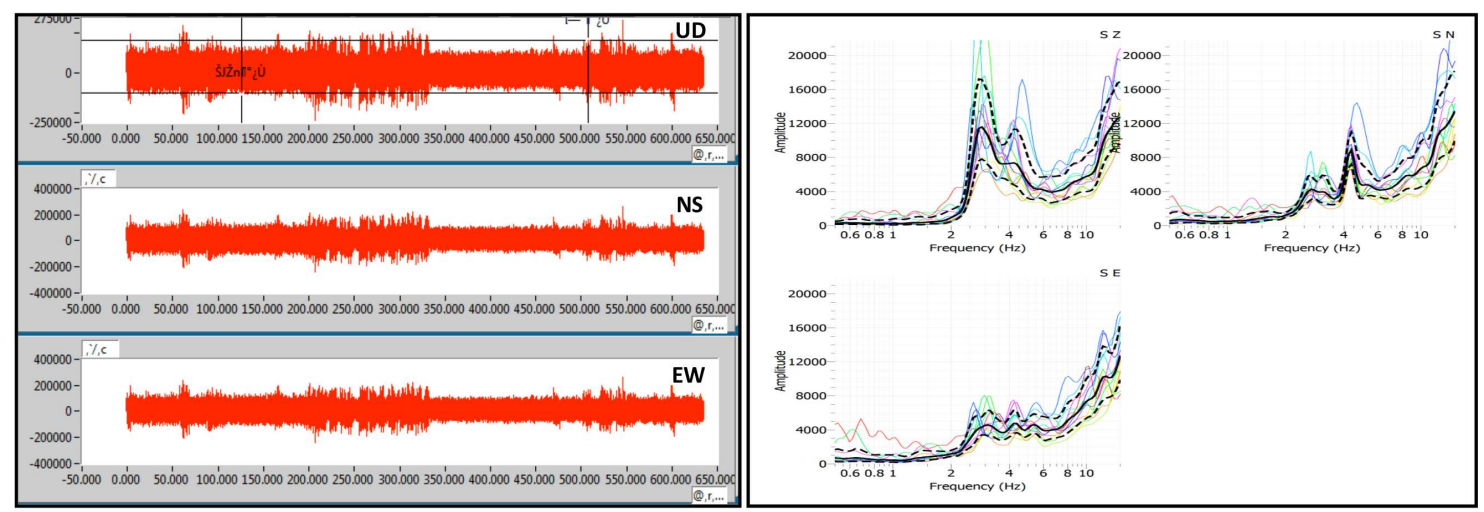

Figure 3: (a) Typical examples of three components of the H/V spectrum ratio (UD, NS and EW) and (b) Typical examples of the Fourier spectra of the three components of the H/V spectrum ratio (UD, NS and EW). 


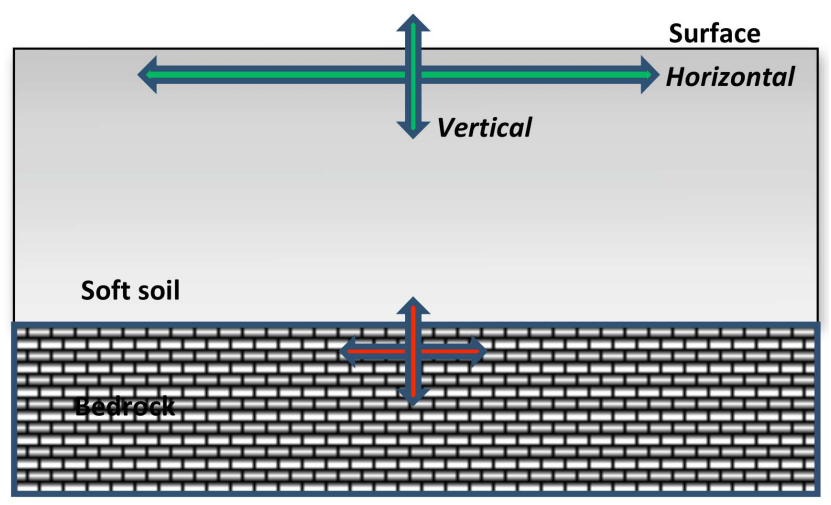

Figure 4: Principle of $\mathrm{H} / \mathrm{V}$ spectrum methods (Nakamura, 2000).

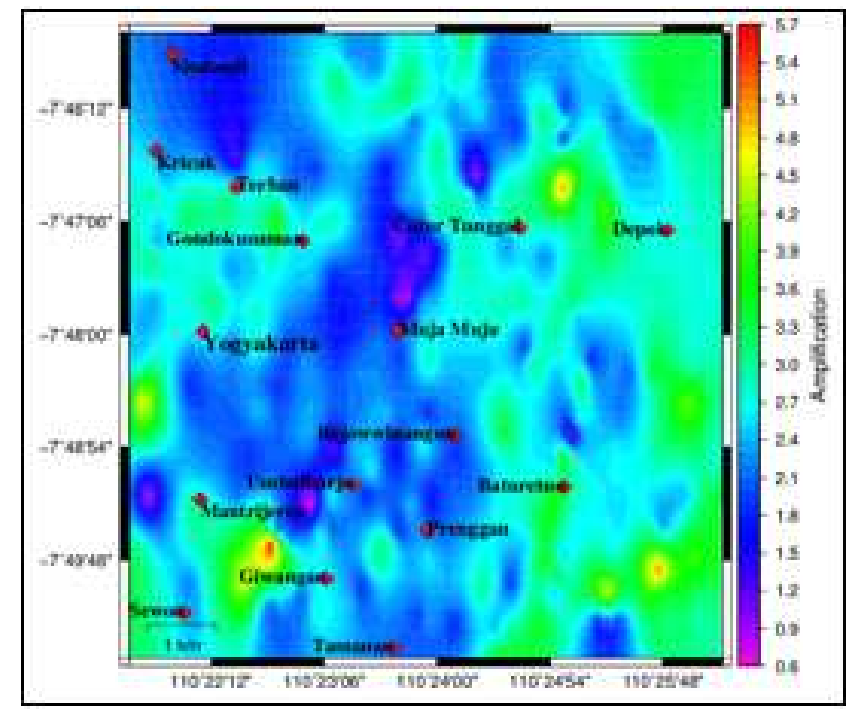

Figure 6: The transfer functions or the amplification factor.

$$
\begin{aligned}
A M P & =\frac{\text { Spectrum of surface horizontal motion }}{\text { Spectrum of horizontal motion of baserock }} \\
& =\propto \frac{\text { Spectrum of surface horizontal motion }}{\text { Spectrum of surface vertical motion }}
\end{aligned}
$$

This equation enables to determine the natural frequency of the surface deposit by simply using the surface records of microtremor. Thus, it is expected that the surface deposit is classified into the viewpoint of earthquake response. The Figure 5 exhibits the transfer function or the amplification spectra of boreholes in the eastern part of Yogyakarta City.

In Figure 6, the amplification factor generally ranges between 0.70 and 5.56. The high ampli- fication mainly related to thicker sediment area where fundamental frequency is low, and vice versa: the lower amplification is in shallow sediment area where high fundamental frequency is dominant. The highest amplification zones are bounded in Terban, Gondokusuman, Yogyakarta, Mantrijeron, Baturetno, Catur Tunggal and Depok areas where are thick sediment area and it should be contributed to construct the new huge building plan or project via engineering point of view. The lowest amplification zones are represented in dark blue colour which is included in Sinduadi, Kricak, north of Terban, south of Yogyakarta, Muja Muja, Rejowwinangun and Umbulharjo, Prenggan, Sewon, Tamanan area (shallow sediment area).

\section{Fundamental frequency}

Estimation of the local response of a site is a key component of any analysis of local seismic hazard. Seismic hazards enable us to characterize potential seismic aggressions that need to be taken into account while designing new structures or upgrading existing ones. The experimental methods involving microtremor recordings are useful for determining site effects in regions of moderate seismic activity like the eastern part of Yogyakarta city where ground motion records are few with highly dense urban population where the noise level is high. Therefore, each observation point provides a spectral ratio and enables an estimation of the fundamental frequency and the maximum value of the amplification at the site studied.

As shown in Figure 7, the fundamental frequency generally varies between 0.40 and 3.30 and there are three zones of frequency which is low, medium and high frequency zones. Kricak, Terban, Gondokusuman, Catur, Tunggal, Depok, Muja Muju, Rejowwinangun, Umbulharjo, Baturetno, Prenggan, Giwangan and Tamanan area are detected the low frequency zones $(<1.00 \mathrm{~Hz})$. So it is clear that the low frequency zone is correlated to the thicker sediment and higher amplification zone where it can be expected the ground motion in the future. Sinduadi, south of Yogyakarta and Mantrijeron and Sewon area are observed 


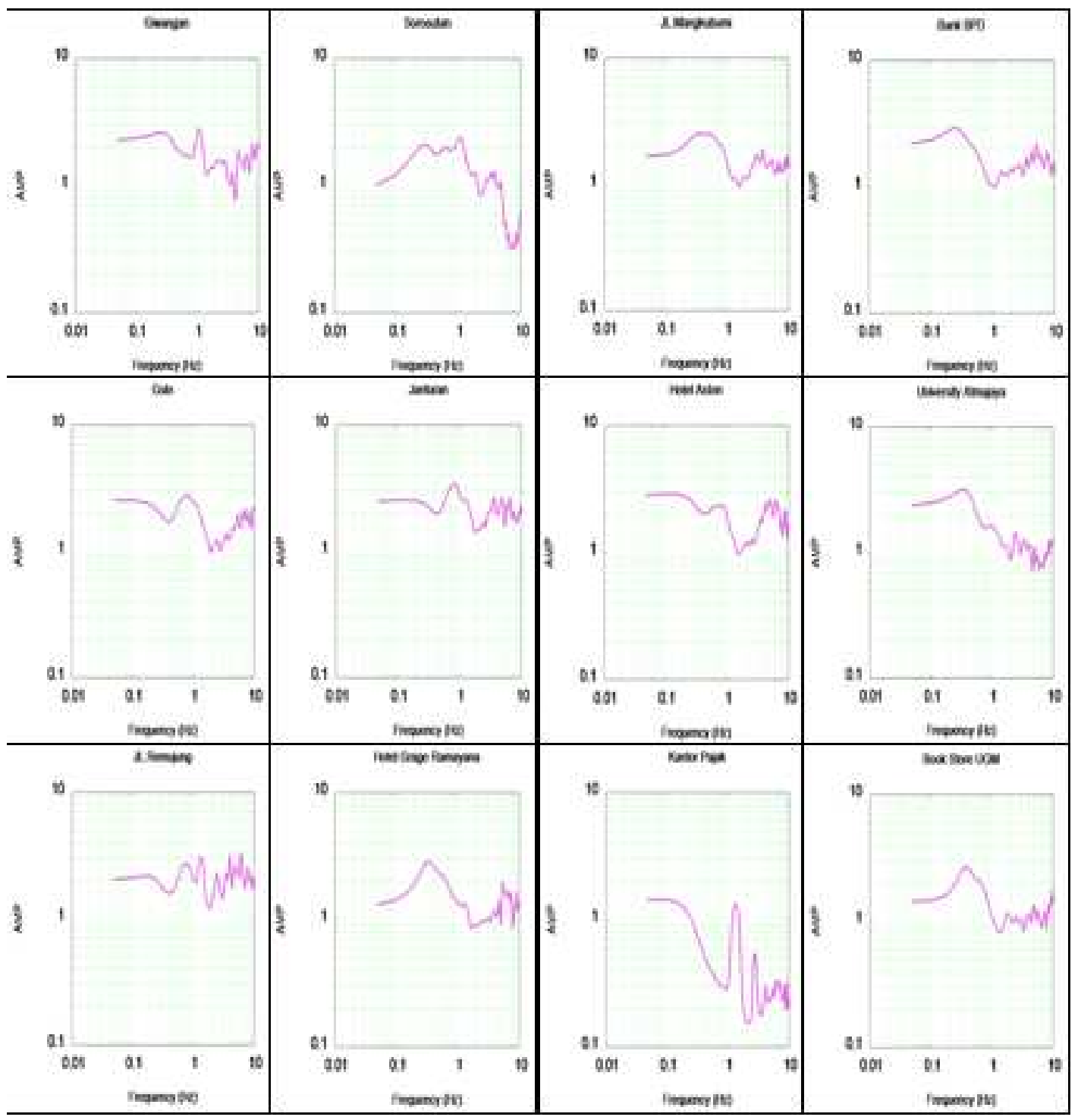

Figure 5: The transfer function or amplification spectra at drilling sites. 


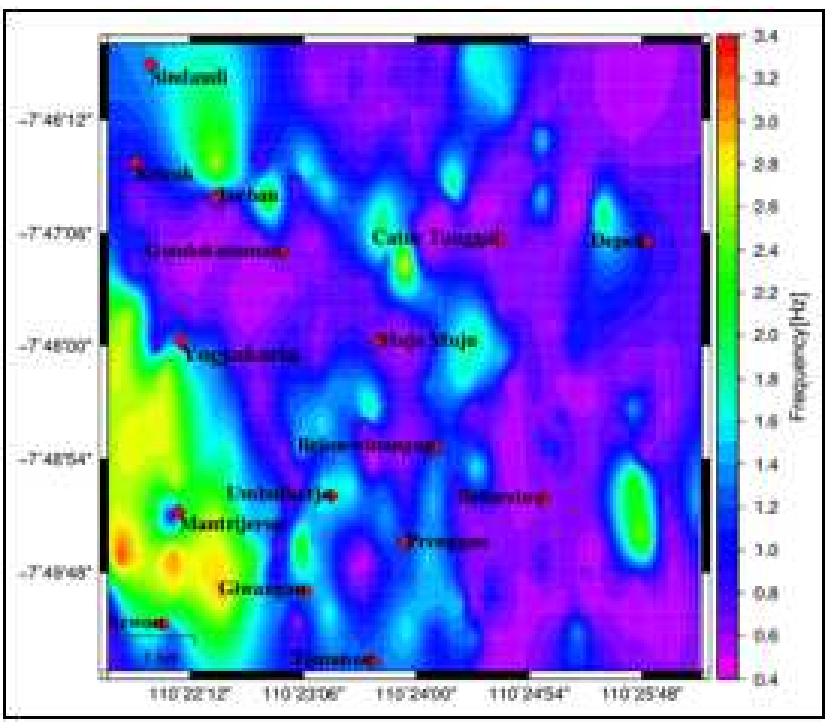

Figure 7: The fundamental frequency.

as the medium frequency zones $(1.6-2.6 \mathrm{~Hz})$. Moreover, it is noticed that small area between Mantrijeron and Giwangan area takes place in high frequency zones $(>2.8 \mathrm{~Hz})$. It means that high frequency zones are related to shallow sediments and low amplification zones. The general relationship between fundamental frequency of peak $\mathrm{H} / \mathrm{V}$ ratio and sediment thickness are shown in the following Table 1 .

\section{Evaluation of shear wave velocity structures}

The shear-wave velocity of soils plays an important role in the design of geotechnical structures under dynamic loads. Mapping of shear wave velocity profile has been widely used in seismic hazard and microzonation studies. A complete site characterization is essential for the seismic site classification and site response studies, which can be used together for seismic microzonation. Site characterization should include an evaluation of subsurface features, subsurface material types, subsurface material properties and buried/hollow structures to determine whether the site is safe against earthquake effects not, such as site amplification. The theoretical evaluation of strong motions and site effects requires information on shear wave velocity structures, especially for sedi- mentary layers overlying on bedrock, such as in Yogyakarta City.

The $27^{\text {th }}$ May 2006 earthquake caused severe damage in Yogyakarta Depression, especially in Yogyakarta city. One main reason for such severe damage is ground amplification due to underlying soil deposit. The most influential parameter in determining the ground amplification in strong ground motion is the subsurface shear-wave velocity structure. Therefore, shear wave velocity structures were determined by geotechnical approach based on SPT values.

\section{Geotechnical approach to S-wave velocity structure}

The standard penetration tests (SPT) were performed at twelve boring sites in the eastern part of Yogyakarta City together with drilling programs. The SPT test was conducted at every 1.5 and $2 \mathrm{~m}$ interval in bore holes which these data are from secondary boring sites. These results are basically related to shear wave velocity. Then, the average $\mathrm{N}$-values are calculated for each layer of evaluated subsurface soil profiles by using the following equation (Fathani et al., 2008).

$$
N=\frac{\sum_{i=1}^{n} t_{i}}{\sum_{i=1}^{n} t_{i} / N_{i}}
$$

where,

$t_{i}=$ thickness of $i^{\text {th }}$ soil layer

$N_{i}=$ recorded blows number of $i^{\text {th }}$ soil layer

$n=$ number of soil layer

Meanwhile, the S-wave velocity structures were determined by using empirical equations which mainly focused on SPT values (Yoshida et al., 2004) for comparative analysis:

$$
V s_{i}=100 N_{i}^{1 / 3}\left(1 \leq N_{i} \leq 25\right)
$$

(for sandy soil)

$$
V s_{i}=80 N_{i}^{1 / 3}\left(1 \leq N_{i} \leq 50\right)
$$

(for clayey soil)

where, $N$ is average number of blows in SPT 
Table 1: General relationship of peak frequency of $\mathrm{H} / \mathrm{V}$ ratio and sediment thickness.

\begin{tabular}{cccccc}
\hline Frequency, $F_{0}(\mathrm{~Hz})$ & $1-1.5$ & $1.6-2$ & $2.1-2.5$ & $2.6-3$ & $>3$ \\
\hline Sediment thickness $(\mathrm{m})$ & $35-50$ & $30-35$ & $20-25$ & $15-20$ & $<15$ \\
\hline
\end{tabular}

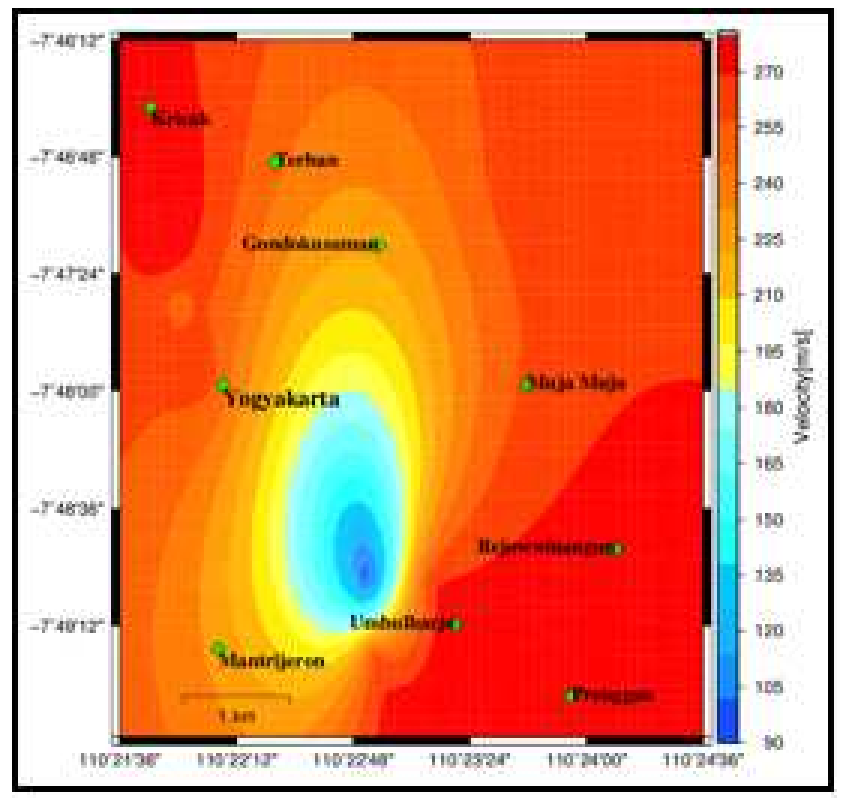

Figure 9: The shear wave velocity structure based on the average Standard Penetration Test (SPT).

Moreover, the soil classification is decided by using the results of site investigations of standard penetration testing at 12 bore holes. From SPT results, the values of N until a depth of 20$40 \mathrm{~m}$ are shown in Figure 8. The average values of $\mathrm{N}$ are used for determining the soil classification on each site. By using Equation 3, the average values of $\mathrm{N}$ until a depth of $20-40 \mathrm{~m}$ at the sites surrounding the eastern part of Yogyakarta City vary from 23.54 to 34.42 .

In Figure 9, according to the average Standard Penetration Test (SPT), the shear wave velocity of the downtown of the south of Yogyakarta is underlain by soft soil condition $\left(<175 \mathrm{~ms}^{-1}\right)$. However, Kricak, Terban, Godokusuman, Yogyakarta, Muja Muju, Rejowwinangun, Mantrijeron, Umbulharjo and Prenggan areas are investigated by medium soil $\left(>175 \mathrm{~ms}^{-1}\right)$. Therefore most of the research area homogeneously lie in the medium soil based on the average Standard Penetration Test (SPT) in Yogyakarta City. The ground motion can be influenced by the shear wave velocity at soft soil condition, especially in urban area study.

\section{Conclusion}

Microtremor and shear-wave velocity usage are widely promoted in studying site effects and seismic motion. Today, the role of site effects in the size of earthquake damage is completely clear. Therefore, in this study, the site effects are analysed by using microtremor and shearwave velocity with geotechnical approach to SPT (Standard Penetration Test). The results of such studies lead in making natural frequency, amplification factor, and S-wave velocity maps. A problem in studying urban zones is that the ground is covered by dense population, roads and constructions. Therefore, it was a little bit difficult to avoid high noise in urban area, yet microtremor is the cheapest and most applicable way in studying such zones. In this research, the single microtremor observation are studied at 274 stations. Both the high amplification factors and the low natural frequency based on the H/V spectrum are reflected to the thicker sediments area where the ground motion can be expected in these area in the future earthquakes. Similarly, the seismic motion can be influenced by the shear wave velocity in SPT of existing drilling sites at soft soil condition especially in urban area study. Concerning the number of stories and importance of the buildings, they should be constructed in the areas of the low amplification factor, the high natural frequency and the high S-wave velocity. Finally, the places located in the best area regarding to the geological engineering and seismicity should be selected for such buildings. 


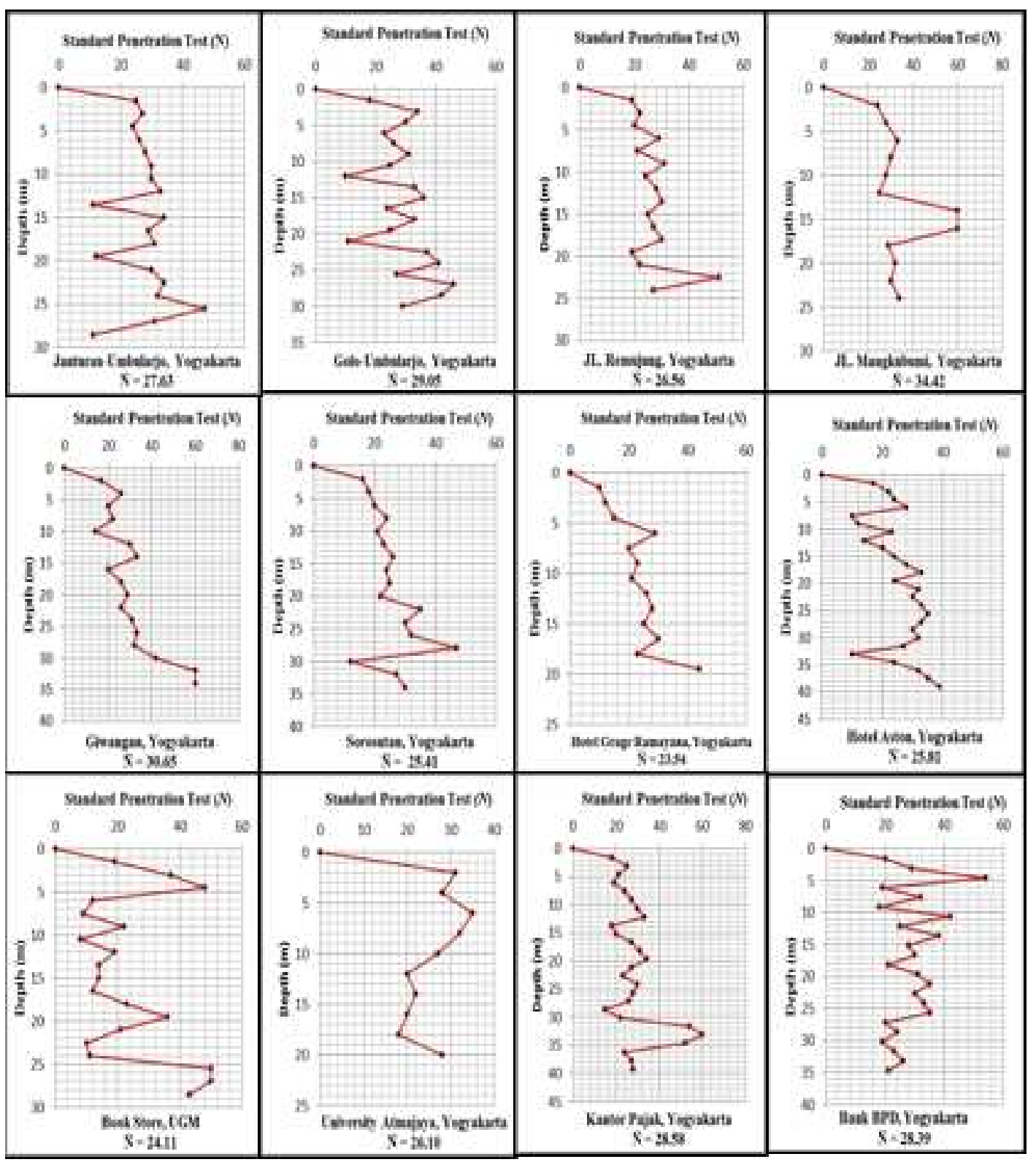

Figure 8: The results of Standard Penetration Test (SPT). 


\section{Acknowledgements}

This study has been supported financially by AUN/SEED-Net, JICA. The author would like to acknowledge and express his sincere thanks and appreciations to Dr. Subagyo Pramumijoyo and Professor Dr. Junji Kiyono from UGM and Kyoto University. The author would like to extend his gratitude to Dr. Salahuddin Husein, Assistant Professor of Geological Engineering Department, UGM, for his constructive comments on this research.

\section{References}

Fathani, T. F., Adi, A. D., Pramumijoyo, S. and Karnawati, D. (2008) The Determination of Peak Ground Acceleration at Bantul Regency, Yogyakarta Province, Indonesia, The Yogyakarta earthquake 2006, star publishing company, Canada.

Nakamura, Y. (1989) A Method for dynamic characteristics estimation of surface layers using microtremor on the surface, RTRI Report 4, 18-27.

Nakamura, Y. (2000) Clear identification of fundamental idea of Nakamura's technique and its applications, Proc. of the 12th World Congresss on Earthquake Engineering, Aucklland, New Zealand.

Tokimatsu, K. Nakajo, Y. and Tamura, S. (1994) Horizontal to vertical amplitude ratio of short period microtremors and its relation to site characteristics. Journal of Structure and Construction Engineering, Architectural Institute of Japan, 475, 1118 (in Japanese).

Yoshida, N. and Suetomi, I. (2004) DYNEQ-A computer program for dynamic response analysis of level ground by equivalent linear method, version 3.25. 